\title{
Spatial distribution of F-net moment tensors for the 2005 West Off Fukuoka Prefecture Earthquake determined by the extended method of the NIED F-net routine
}

\author{
Takumi Matsumoto $^{1}$, Yoshihiro Ito ${ }^{1}$, Hirotoshi Matsubayashi ${ }^{1}$, and Shoji Sekiguchi ${ }^{1}$ \\ ${ }^{1}$ National Research Institute for Earth Science and Disaster Prevention, Tennodai, 3-1, Tsukuba, Ibaraki 305-0006, Japan \\ (Received August 10, 2005; Revised November 22, 2005; Accepted November 28, 2005; Online published January 27, 2006)
}

\begin{abstract}
The 2005 West Off Fukuoka Prefecture Earthquake with a Japan Meteorological Agency (JMA) magnitude $\left(\mathrm{M}_{I M A}\right)$ of 7.0 occurred on March 20, 2005. We determined moment tensor solutions, using a surface wave with an extended method of the NIED F-net routine processing. The horizontal distance to the station is rounded to the nearest interval of $1 \mathrm{~km}$, and the variance reduction approach is applied to a focal depth from $2 \mathrm{~km}$ with an interval of $1 \mathrm{~km}$. We obtain the moment tensors of 101 events with $\left(\mathrm{M}_{{ }_{M A}}\right)$ exceeding 3.0 and spatial distribution of these moment tensors. The focal mechanism of aftershocks is mainly of the strike-slip type. The alignment of the epicenters in the rupture zone of the main-shock is oriented between $\mathrm{N}_{110}{ }^{\circ} \mathrm{E}$ and $\mathrm{N} 130 \mathrm{E}$, which is close to the strike of the main-shock's moment tensor solutions $\left(\mathrm{N} 122^{\circ} \mathrm{E}\right)$. These moment tensor solutions of intermediatesized aftershocks around the focal region represent basic and important information concerning earthquakes in investigating regional tectonic stress fields, source mechanisms and so on.
\end{abstract}

Key words: The 2005 West Off Fukuoka Prefecture Earthquake, moment tensor, broadband seismometer, seismicity, F-net.

\section{Introduction}

The 2005 West Off Fukuoka Prefecture Earthquake $\mathrm{M}_{\text {ma }} 7.0$ that occurred at 1:53 a.m. (UT) on March 20, 2005 is the first M7-class intra-plate earthquake in the northern Kyushu district after F-net, the broadband seismograph network of the National Research Institute for Earth Science and Disaster Prevention (NIED) was established with a dense and homogeneous distribution all over Japan. The seismicity around the northern Kyushu district is very low. An M7-class earthquake occurred near Iki and Tsushima in 1700 , and this is the only earthquake that occurred historically around this region (The Headquarters for Earthquake Research Promotion, 1997). Seno (1999) estimated the stress field around Japan. This model indicates the maximum compressive stress direction from E-W to ENE-WSW in the northern Kyushu district. It is consistent with the maximum compressive stress direction indicated by the focal mechanisms of background seismicity, which is determined by NIED moment tensor routine processing (Fig. 1).

Earthquake focal mechanisms represent basic and important information in the seismology and have been utilized to understand the regional tectonic stress fields and the source mechanisms of large earthquakes, and to simulate the strong motion and so on.

In order to estimate the distribution of the source fault in and around the focal area of the 2005 west off Fukuoka prefecture earthquake, Ito et al. (2006) mainly employed

Copyright (c) The Society of Geomagnetism and Earth, Planetary and Space Sciences (SGEPSS); The Seismological Society of Japan; The Volcanological Society of Japan; The Geodetic Society of Japan; The Japanese Society for Planetary Sciences; TERRAPUB. the centroid moment tensor inversion method to calculate the centroid location, time and moment tensor solutions of the main shock and aftershocks with a magnitude more than 4, velocity and acceleration seismograms of the F-net broadband seismometers and Hi-net tiltmeters. They also estimate the direction of rupture propagation of the main shock and finally discuss the initiation and termination of the rupture of the main shock controlled by fault bends.

In this study, we thoroughly investigate almost all the spatial distribution of moment tensors of the main-shock and their intermediate-sized aftershocks with a magnitude less than 4, through the extended method of the NIED Fnet routine processing. In this analysis, moment tensor solutions and centroid depths were only calculated by using waveforms observed at three stations, with the fixed epicenters in the JMA Catalogue. We finally discuss the relationship between the distribution of moment tensor solutions and the coseismic-slip area of the main shock.

\section{Moment Tensor Inversion}

Waveform data are obtained from the F-net, the broadband seismograph network of NIED installed at intervals of $100 \mathrm{~km}$ in Japan (Okada et al., 2004) (Fig. 1). A threecomponent broadband seismometer (STS-1/2) and a threecomponent strong motion velocity-type seismograph (VSE$355 \mathrm{G} 2 / \mathrm{G} 3$ ) have been respectively installed at each station. We have been routinely analyzing earthquakes of magnitude greater than 3.5 based on the unified hypocenter catalog maintained by the Japan Meteorological Agency (JMA) (Fukuyama et al., 1998). All results of the moment tensor analysis using surface wave are available or accessible 
Table 1. Structure model.

\begin{tabular}{rcccccc}
\hline $\begin{array}{c}\text { Depth } \\
(\mathrm{km})\end{array}$ & $\begin{array}{c}\text { Thickness } \\
(\mathrm{km})\end{array}$ & $\begin{array}{c}V p \\
(\mathrm{~km} / \mathrm{s})\end{array}$ & $\begin{array}{c}V s \\
(\mathrm{~km} / \mathrm{s})\end{array}$ & $\begin{array}{c}\text { Density } \\
\left(\mathrm{kg} / \mathrm{m}^{3}\right)\end{array}$ & $Q p$ & $Q s$ \\
\hline 0 & 3 & 5.500 & 3.140 & 2300 & 600 & 300 \\
3 & 15 & 6.000 & 3.550 & 2400 & 600 & 300 \\
18 & 15 & 6.700 & 3.830 & 2800 & 600 & 300 \\
33 & 67 & 7.800 & 4.460 & 3200 & 600 & 300 \\
100 & 125 & 8.000 & 4.570 & 3300 & 600 & 300 \\
225 & 100 & 8.400 & 4.800 & 3400 & 600 & 300 \\
325 & 100 & 8.600 & 4.910 & 3500 & 600 & 300 \\
425 & 60 & 9.300 & 5.310 & 3700 & 600 & 300 \\
485 & 60 & 9.713 & 5.467 & 3850 & 600 & 300 \\
545 & 60 & 9.914 & 5.624 & 3950 & 600 & 300 \\
605 & 60 & 10.120 & 5.781 & 4030 & 600 & 300 \\
665 & 60 & 10.880 & 6.041 & 4380 & 600 & 300 \\
725 & - & 11.060 & 6.201 & 4500 & 600 & 300 \\
\hline
\end{tabular}

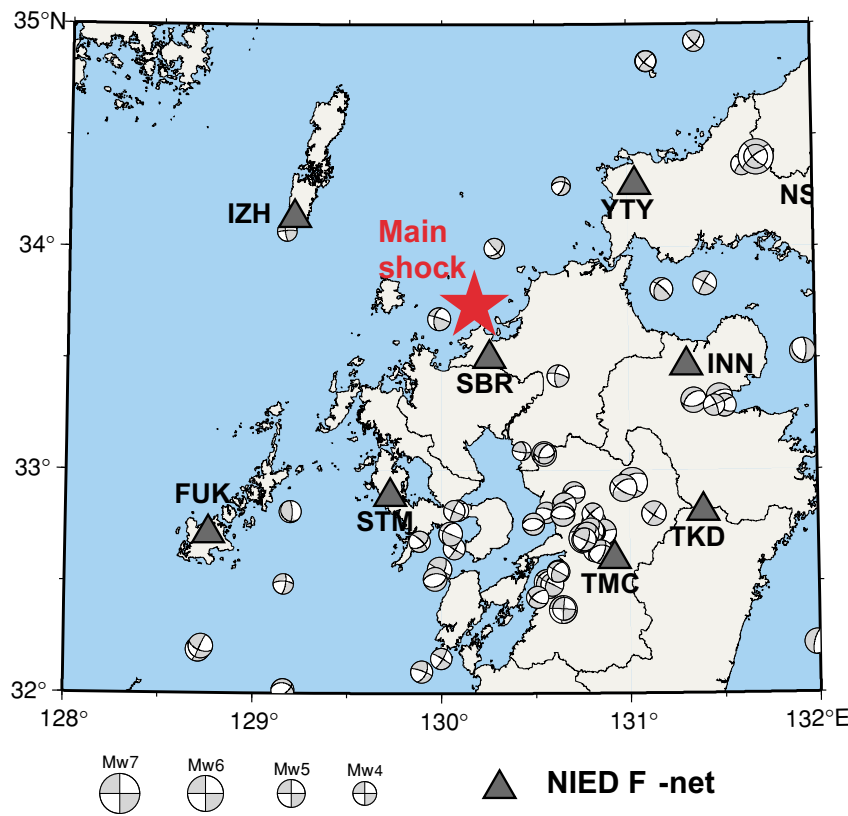

Fig. 1. Station distribution and seismicity around northern Kyushu, Japan. Focal mechanisms less than $25 \mathrm{~km}$ in depth occurred from January 1997 until March 20, 2005. The red star indicates the epicenter of the 2005 West Off Fukuoka Prefecture Earthquake, which occurred on March 20, 2005 (JMA, 2005). Black triangles show the NIED F-net stations.

through the Internet (http://www.fnet.bosai.go.jp/). These source parameters are used as the initial condition in the waveform inversion for the rupture process (e.g. Honda et al., 2004, Sekiguchi et al., 2006). In our routine analysis, different bandpass filters are used according to the magnitude $\mathrm{M}_{M A}$, estimated by the JMA (2005): 0.02-0.05, 0.010.05 and $0.005-0.02 \mathrm{~Hz}$ pass band are used for the magnitude ranges of $3.5 \leq \mathrm{M}_{I M A}<5.0,5.0 \leq \mathrm{M}_{M A}<7.5$, and 7.5 $\leq \mathrm{M}_{I M A}$, respectively.

Green's function is computed by using the discrete wavenumber method developed by Saikia (1994), whose code is called FKPPROG. The velocity structure used for Green's function is shown in Table 1. This structure is the same as the NIED F-net routine, and is based on Ukawa et al. (1984) for the shallower parts, Fukao (1977) for the middle deep parts, and iasp91 (Kennett and Engdahl, 1991) for the deeper parts. Variance reduction $(V R)$, which indicates the fit between observed and synthetics, is computed by the following equation:

$$
V R(\%)=100 \times \sum_{i} w_{i} \int\left(1-\frac{\left(s_{i}(t)-o_{i}(t)\right)^{2}}{\left|o_{i}(t)\right|^{2}}\right) d t
$$

where $s_{i}(t)$ and $o_{i}(t)$ are synthetic and observed waveforms at station $i$, respectively. $w_{i}$ is a weighting function proportional to the hypocentral distance (Fukuyama and Dreger, 2000). We select moment tensors whose $V R$ is greater than $50 \%$. The fixed epicenter locations are taken from the unified JMA hypocenter catalog. The horizontal distance from the epicenter to the station is rounded to the nearest interval of $5 \mathrm{~km}$. The variance reduction approach has also been applied to focal depths from $5 \mathrm{~km}$ with an interval of $3 \mathrm{~km}$. The results with maximum variance reduction are taken as the optimal focal depth.

In order to analyze moment tensor solutions for small earthquakes as far as possible, our new approach differs from that of the NIED F-net routine in the following respects: (a) The horizontal distance to the station is rounded to the nearest interval of $1 \mathrm{~km}$. (b) The variance reduction approach was also applied to focal depths from $2 \mathrm{~km}$ with an interval of $1 \mathrm{~km}$ (Matsumoto et al., 2006). (c) Filters with passbands of $0.02-0.05 \mathrm{~Hz}$ are used for a magnitude range of $3.0 \leq \mathrm{M}_{I M A}<5.0$. We can implement this advanced approach in the NIED F-net routine with a slight increase in processing time.

\section{Results}

From March 20 until June 30, 99 events with a magnitude exceeding 3.5 were listed in the JMA Catalog. In the NIED F-net routine, whose $V R$ exceeded 50 percent and more than 3 stations were used, we obtained the moment tensors of 62 events. On the other hand, in this study, 272 events with a magnitude exceeding 3.0 were listed in the JMA Catalog, 
Table 2. Source parameters obtained for the mainshock and the largest aftershock.

\begin{tabular}{lcccccc}
\hline & \multicolumn{3}{c}{ Main-shock } & \multicolumn{3}{c}{ Largest aftershock } \\
\hline & $\begin{array}{c}\text { F-net } \\
\text { (this study) }\end{array}$ & USGS & Harvard & $\begin{array}{c}\text { F-net } \\
\text { (this study) }\end{array}$ & USGS & Harvard \\
\hline Date/time (UT) & \multicolumn{2}{c}{$2005 / 03 / 2001: 53$} & \multicolumn{2}{c}{$2005 / 04 / 1921: 11$} \\
Depth (km) & 10 & 13 & 12 & 8 & 18 & 17 \\
Mw & 6.6 & 6.5 & 6.6 & 5.6 & 5.5 & 5.4 \\
Strike (degree) & $213 / 122$ & $124 / 34$ & $122 / 32$ & $132 / 226$ & $57 / 149$ & $42 / 132$ \\
Dip (degree) & $83 / 83$ & $87 / 89$ & $89 / 82$ & $79 / 69$ & $78 / 81$ & $88 / 86$ \\
Rake (degree) & $-173 /-7$ & $1 / 177$ & $8 / 179$ & $-21 /-168$ & $171 / 12$ & $176 / 2$ \\
\hline
\end{tabular}

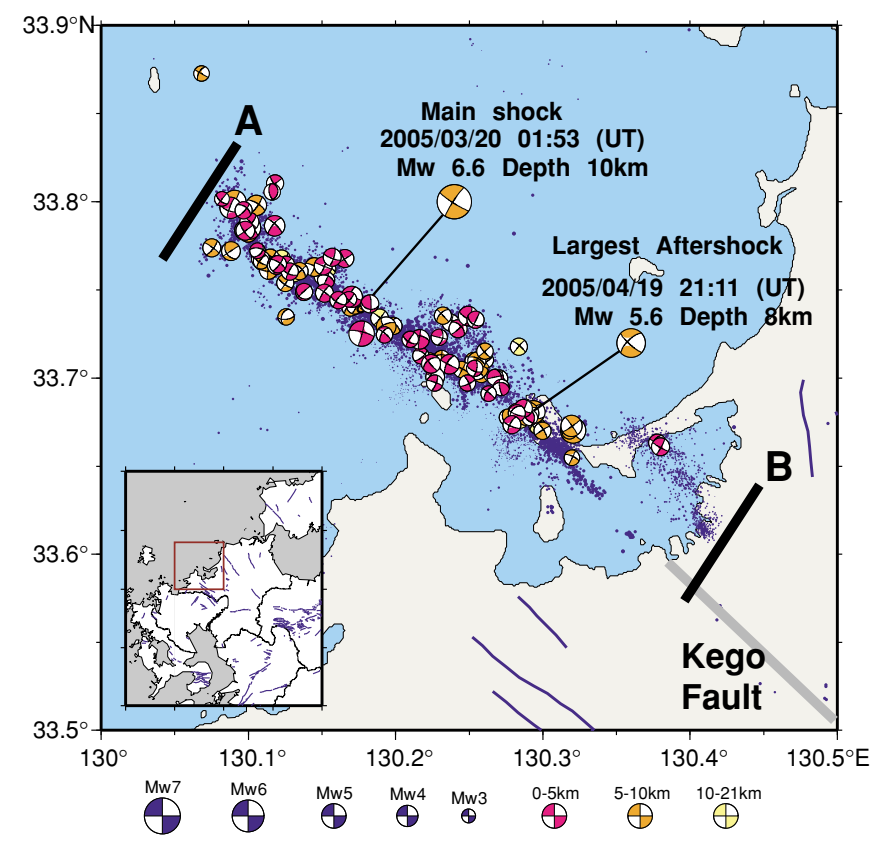

(a)

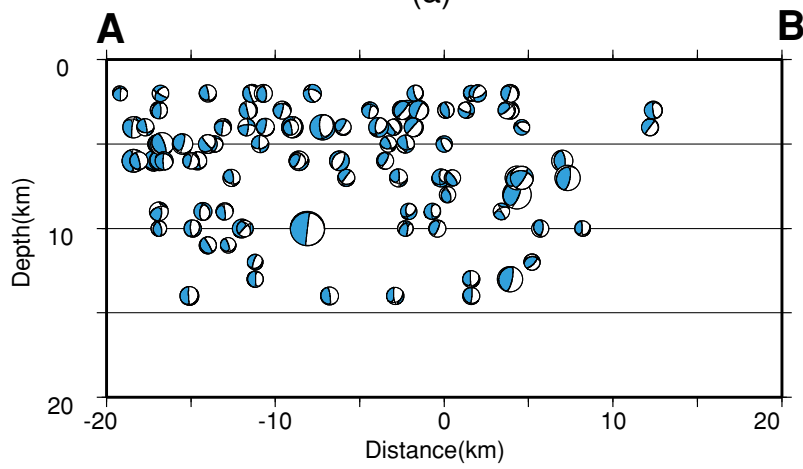

(b)

Fig. 2. Focal mechanism distribution. (a) Map-view. The color of the moment tensors indicates the depth, while blue dots indicate epicenters and bule lines indicate active faults. (b) The cross section along A-B in (a).

and the moment tensors of 101 events were determined. In the moment magnitude range of $\mathrm{M} w \leq 4.0, V R$ in this study went up 5 percent from that of F-net routine processing. In the moment magnitude range of $\mathrm{Mw}>4.0, V R$ in this study was almost equal to that of F-net routine processing.

The spatial distribution of the moment tensors that were determined in this study is shown in Fig. 2. We successfully obtain the moment tensors of the main-shock with very good variance reduction. The centroid depth error of these moment tensors is estimated to within $5 \mathrm{~km}$ (Fukuyama and Dreger, 2000), while the epicenter error of these events listed in the JMA Catalog is estimated to within $0.5 \mathrm{~km}$. We use the fixed epicenter in the JMA Catalogue and the horizontal distance to the station rounded to the nearest interval of $1 \mathrm{~km}$, then the location error of the horizontal direction is estimated to within $1 \mathrm{~km}$. One of the nodal planes of the moment tensor solution is consistent with aftershock distribution. The source parameters for the main-shock and the largest aftershock are shown in Table 2 and are similar to those listed in the USGS CMT and Harvard CMT Catalogs. The focal mechanisms of the main-shock and the largest aftershock are of the strike-slip type.

We determined many moment tensor solutions of intermediate-sized aftershocks around the focal region. The Harvard CMT catalog effectively covers earthquakes with $\mathrm{M} w>5.3$, the NIED F-net routine MT catalog those with $\mathrm{M} w>3.8$ (Kubo et al., 2002), and this study those with $\mathrm{M} w>3.5$.

However, we were unable to determine the moment tensors of 35 events which occurred within 4 hours of the mainshock in the NIED F-net routine, and of the 90 events in this study. When a large earthquake occurs, it is difficult to perform waveform inversion with the swarm of the aftershock. In the case of the 2004 Mid Niigata earthquake ( $\mathrm{M}_{M A}$ 6.8) and the 2003 Tokachi-Oki earthquake (M $\mathrm{M}_{M A}$ 8.0), we were also unable to determine the moment tensors of aftershocks for 3 or 4 hours after the main-shock.

As a result, we obtained 101 moment tensors solutions distributed around the focal region.

\section{Discussion}

We thoroughly determined the moment tensor solutions of the main shock and intermediate-sized aftershocks around the focal region. As shown in Fig. 2, the focal mechanism of aftershocks obtained in this study is mainly of the strike-slip type. The trend of the epicenter distribution may correspond to the strike direction of the focal mechanism. The alignment of the epicenters in the rupture zone of the main-shock is oriented between $\mathrm{N} 110^{\circ} \mathrm{E}$ and $\mathrm{N} 130^{\circ} \mathrm{E}$, which is close to the strike of the main-shock's moment tensor solutions (NIED: N122E; USGS: N124E; Harvard: N122E). In the southeastern part of the focal region, we determined only two moment teonsor solutions. In this region, Imanishi 


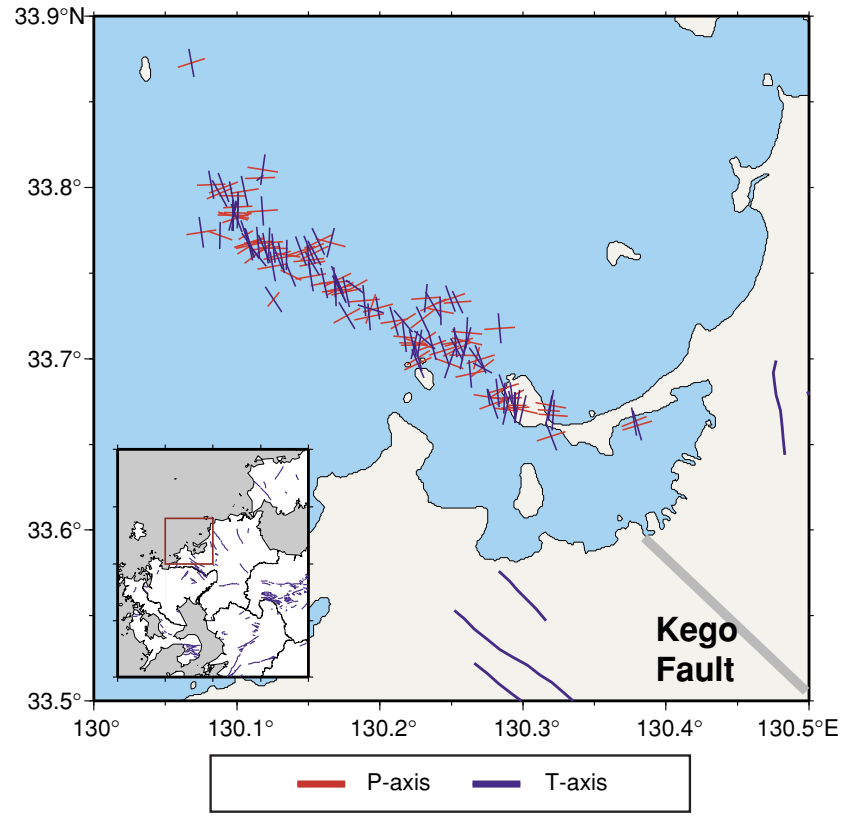

Fig. 3. Distributions of horizontally projected $P$-axis (pseudo $P$-axis) and $T$-axis (pseudo $T$-axis) azimuth directions. Red is $P$-axis, Blue is $T$-axis.

et al. (2006) determined the double-difference earthquake locations and focal mechanism solutions, these focal mechanisms are comparable with our study.

Figure 3 represents the $P$ - and $T$-axes distribution of all moment tensor solutions. These $P$-axes with the direction from E-W to ENE-WSW are comparable with those of the stress field (Seno, 1999) in this region. However, there are some aftershocks with $P$ - and $T$-axes being different from those of the main shock.

To show the similarity between the focal mechanisms of the main-shock and the aftershock, we used Kagan's angle (Kagan, 1991) defined as the minimum angle of rotation from one mechanism to the other in $3-\mathrm{D}$, which varies from 0 to $120^{\circ}$. Figure 4 represents the Kagan's angle distribution and the distributions of coseismic slip estimated by using strong ground motion data (Sekiguchi et al. 2006); the focal mechanisms colored red or pink are similar to the main-shock with a Kagan's angle of less than 30 degrees. In the inflection-point and the eastern part of the epicenter distribution, there are aftershocks with a Kagan's angle above 45 degrees.

The large aftershocks with $\mathrm{Mw}>5.0$ occurred in the area within $1 \mathrm{~m}$ of the main shock's slip. The intermediatesize aftershocks with a Kagan's angle less than 15 degrees occurred in the area within $1 \mathrm{~m}$ of the main shock's slip except the aftershocks in the largest slip area with $2 \mathrm{~km}$ depth. Nishimura et al. (2006) also estimated coseismic slip distribution with ground deformation date observed by GPS and InSAR. They proposed that large slip area is concentrated at depths of 0 to $10 \mathrm{~km}$ in an along-strike range from the hypocenter to $10 \mathrm{~km}$ east-southeast of it. The intermediate-size aftershocks with a Kagan's angle less than 15 degrees also occurred in the area within $1 \mathrm{~m}$ of the main shock's slip except the aftershocks in the largest slip area with $4 \mathrm{~km}$ depth.

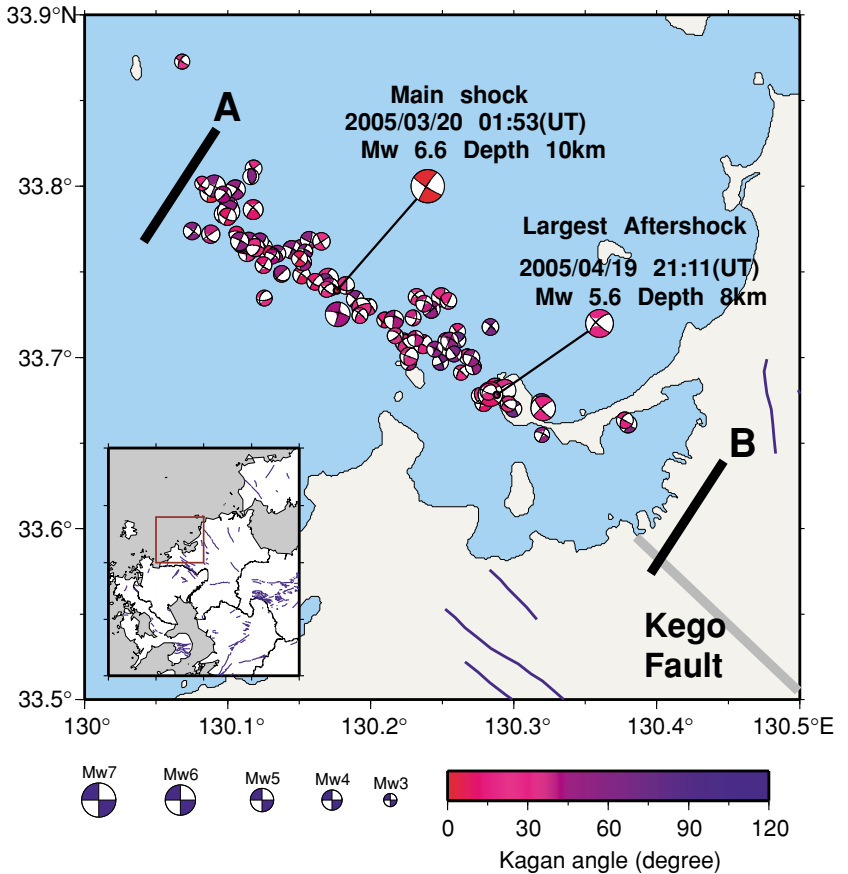

(a)

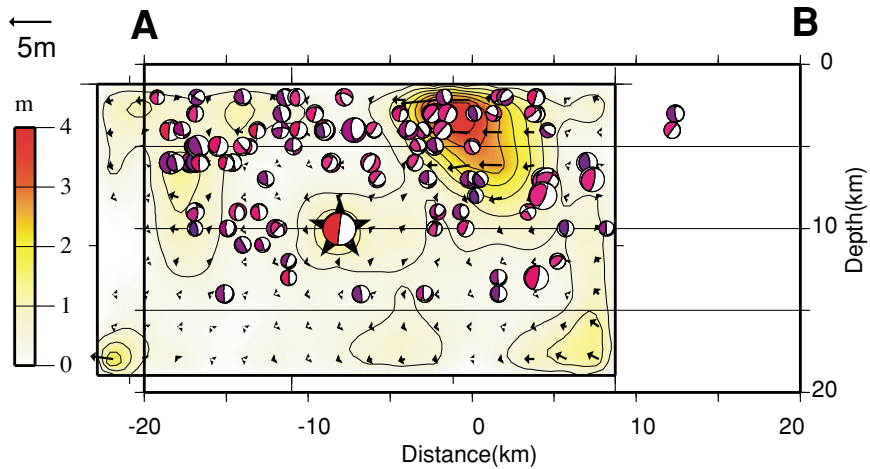

(b)

Fig. 4. Focal mechanism distribution. Color of moment tensors indicates the Kagan's angle. (a) Map-view. Blue lines indicate an active fault. (b) The cross section along A-B in (a) with distributions of coseismic slip obtained for the 2005 West Off Fukuoka Prefecture Earthquake by Sekiguchi et al. (2006). Arrows show the amplitude and directions of slip. Contour interval is $0.5 \mathrm{~m}$.

On the other hand, the clear inflection-point of epicenter distribution is near $130.28^{\circ} \mathrm{E}$. In the eastern part of the focal region, the alignment of the epicenters is oriented between $\mathrm{N} 125^{\circ} \mathrm{E}$ and $\mathrm{N} 145^{\circ} \mathrm{E}$, which is close to the strike of the largest aftershock's moment tensor solutions. It occurred within the northwestern extent of the Kego fault, and the strike direction in the focal mechanism is consistent with that of the Kego fault.

It is possible that the largest aftershock occurred in another fault plane. For example, Ito et al. (2006) proposed that three different faults exist in this focal region by analyzing CMT solutions with velocity and acceleration seismograms of the F-net broadband seismometers and Hi-net tiltmeters. It seems that these CMT solutions indicate a more accurate mechanism and centroid location due to the use of additional waveform data for the analysis, meaning that 
fault model is also supported by the strike direction of the focal mechanism of the main-shock and large aftershocks determined in this study. On the other hand, assuming the extended approach in the NIED F-net routine can determine more moment tensor solutions with magnitudes exceeding 3.0 all over the focal region, then it is possible that the stress field inferred from the distribution of the $P$ - and $T$-axes and the spatial distribution of the moment tensor solutions with intermediate-sized aftershocks determined in this study are comparable with that fault model.

The NIED F-net routine processing is basically automated today. By implementing this extended approach in the NIED F-net routine, we will automatically determine the spatial distribution of many moment tensor solutions like this study in semi-real-time to understand the regional tectonic stress fields and source mechanisms of large earthquakes and so on.

\section{Conclusion}

We analyzed the moment tensor solutions with a magnitude exceeding 3.0 listed in the JMA Catalog, with the extended method of the NIED F-net routine processing and consequently obtained 101 moment tensor solutions. The main-shock's moment tensor solution in our study is comparable with the USGS CMT catalog and Harvard CMT catalog. We determined many moment tensor solutions of intermediate-sized aftershocks around the focal region. These moment tensor solutions represent basic and important information concerning earthquakes in investigating regional tectonic stress fields, source mechanisms, fault model and so on.

Acknowledgments. We thank Dr. G. Ekstrom and an anonymous reviewer for comments on the manuscript. We would like to thank the Japan Meteorological Agency (JMA) providing us data from the JMA Catalog (2005). GMT (Wessel and Smith, 1995) was used to make figures.

\section{References}

Fukao, Y., Upper mantle P structure on the ocean side of the Japan-Kurile Arc, Geophys. J. Roy. Astr. Soc., 50, 621-642, 1977.

Fukuyama, E. and D. S. Dreger, Performance test of an automated moment tensor determination system for the future "Tokai" earthquake, Earth Planets Space, 52, 383-392, 2000.

Fukuyama, E., M. Ishida, D. S. Dreger, and H. Kawai, Automated seismic moment tensor determination by using on-line broadband seismic waveforms, J. Seismol. Soc. Japan (Zisin), 51, 149-156, 1998 (in Japanese with English abstract).

Harvard Quick CMTs, http://www.seismology.harvard.edu/projects/CMT, Harvard University, 2005.
Honda, R., S. Aoi, N. Morikawa, H. Sekiguchi, T. Kunugi, and H. Fujiwara, Ground motion and rupture process of the 2003 Tokachi-oki earthquake obtained from strong motion data of K-NET and KiK-net, Earth Planets Space, 56, 317-322, 2004.

Imanishi, K., Y. Kuwahara, and Y. Haryu, Off-fault aftershocks of the 2005 West Off Fukuoka Prefecture Earthquake: Reactivation of a structural boundary?, Earth Planets Space, 58, this issue, 81-86, 2006.

Ito, Y., K. Obara, T. Takeda, K. Shiomi, T. Matsumoto, S. Sekiguchi, and S. Hori, Initial-rupture fault, main-shock fault, and aftershock faults: Fault geometry and bends inferred from centroid moment tensor inversion of the 2005 west off Fukuoka prefecture earthquake, Earth Planets Space, 58, this issue, 69-74, 2006.

Japan Meteorological Agency, The seismological and volcanological Bulletin of Japan, Japan Meteorological Agency, Tokyo, 2005.

Kagan, Y. Y., 3-D rotation of double-couple earthquake sources, Geophys. J. Int., 106, 709-716, 1991.

Kennett, B. L. N. and E. R. Engdahl, Travel times for global earthquake location and phase identification, Geophys. J. Int., 122, 429-465, 1991.

Kubo, A., E. Fukuyama, H. Kawai, and K. Nonomura, NIED seismic moment tensor catalogue for regional earthquakes around Japan: quality test and application, Tectonophysics, 356, 23-48, 2002.

Matsumoto, T., Y. Ito, and H. Matsubayashi, Spatial distribution of F-net Moment Tensor Solutions of the Mid Niigata Prefecture Earthquake in 2004, J. Seismol. Soc. Japan (Zisin), xx, xx-xx, 2006 (in Japanese with English abstract, in press).

Nishimura, T., S. Fujiwara, M. Murakami, H. Suito, M. Tobita, and H. Yarai, Fault model of the 2005 Fukuoka-ken Seiho-oki earthquake estimated from coseismic deformation observed by GPS and InSAR, Earth Planets Space, 58, this issue, 51-56, 2006.

Okada, Y., K. Kasahara, S. Hori, K. Obara, S. Sekiguchi, H. Fujiwara, and A. Yamamoto, Recent progress of seismic observation networks in Japan-Hi-net, F-net, K-NET and KiK-net, Earth Planets Space, 56, xv-xxviii, 2004.

Saikia, C. K., Modified frequency-wavenumber algorithm for regional seismograms using Filon's quadrature: modeling of $\mathrm{Lg}$ waves in eastern North America, Geophys. J. Int., 118, 142-158, 1994.

Seismic Activity in Japan-Regional perspectives on the characteristics of destructive earthquakes, http://www.hp1039.jishin.go.jp/eqchreng/ eqchrfrm.htm, The Headquarters for Earthquake Research Promotion, 1997.

Sekiguchi, H., S. Aoi, R. Honda, N. Morikawa, T. Kunugi, and H. Fujiwara, Rupture process of the 2005 West Off Fukuoka Prefecture earthquake obtained from strong motion data of K-NET and KiK-net, Earth Planets Space, 58, this issue, 37-43, 2006.

Seno, T., Syntheses of the regional stress fields of the Japanese Islands, The Island Arc, 8, 66-79, 1999.

Ukawa, M., M. Ishida, S. Matsumura, and K. Kasahara, Hypocenter determination method of the Kanto-Tokai observational network for microearthquakes, Rep. Nat'l Res. Inst. Earth Sci. Disas. Prev., 53, 1-88, 1984 (in Japanese with English abstract).

USGS Fast Moment Tensor Solutions, http://neic.usgs.gov/neis/FM/, USGS, 2005.

Wessel, P. and W. H. F. Smith, New improved version of the Generic Mapping Tools Released, Eos Trans. Am. Geophys. Union, 79, 579, 1998 .

T. Matsumoto (e-mail: mtakumi@bosai.go.jp), Y. Ito, H. Matsubayashi, and S. Sekiguchi 